\title{
Occurrence and distribution of metals in the outdoor air in Ostrava's agglomeration
}

\author{
K. Lach $^{1}$, R. Muir ${ }^{2}$, P. Danihelka ${ }^{3}$, V. Mička ${ }^{1} \&$ Z. Kaličáková ${ }^{3}$ \\ ${ }^{1}$ Public Health Institute, Ostrava, Czech Republic \\ ${ }^{2}$ Naneum Ltd., Canterbury Innovation Centre, UK \\ ${ }^{3} V \check{S} B$ - Technical University of Ostrava, \\ Faculty of Safety Engineering, Czech Republic
}

\begin{abstract}
In 2011 a series of measurements were started and samples collected to test air quality in two places in the town of Ostrava, a heavily industrialised city in the Czech Republic. As a reference, measurements were also made in Olomouc City, chosen for its much cleaner environment. A Fast Mobility Particle Sizer (FMPS Model 3091, TSI Inc., St.Paul, MN) was used to determine aerosol particle size distributions (5.6 nm to $560 \mathrm{~nm}$ ). A wide range aerosol sampling system (Nano-ID Select, Naneum Ltd., UK) was used to collect size resolved samples in the range from $1 \mathrm{~nm}$ to $30 \mu \mathrm{m}$ on 12 stages. $\mathrm{Mn}, \mathrm{Cr}, \mathrm{Ni}, \mathrm{Fe}, \mathrm{Pb}, \mathrm{As}, \mathrm{Zn}$ and $\mathrm{Cu}$ were analysed at each stage of the Nano-ID sampler using ICP-MS. The morphology of the collected samples was investigated using Scanning Electron Microscopy (SEM).

$\mathrm{Mn}$ and $\mathrm{Cr}$ showed very similar size distributions independent of the sampling place. These two metals are predominantly present in the nano-range. As and partially also $\mathrm{Pb}$ were predominantly accumulated in particles larger than $250 \mathrm{~nm}$ which indicated different sources from $\mathrm{Mn}$ and $\mathrm{Cr}$.

The majority of all particles were composed of iron oxide with a spherical morphology, originating most likely from the local metallurgical industry. The sources of bigger particles containing $\mathrm{As}$ or $\mathrm{Pb}$ were probably products of burning of black coal in heating plants or power plants.

Size dependent distributions of particulate matter measured by FMPS confirm significant dependence on actual meteorological conditions.

Keywords: air pollution, heavy metals, dust composition, metals concentration, metals mass distribution.
\end{abstract}




\section{Introduction}

The potential of particulate matter to induce adverse health effects has long been known. Anthropogenic sources of air pollution are probably one of the most serious environmental problems. It may affect all of us and in many cases leaving little chance of avoiding it. In urban environments especially, anthropogenic sources generally outweigh natural emissions, even with the current trend towards reductions in the former. It is estimated that as a result of airborne dust pollution in Europe some 280,000 people die prematurely each year. Air pollution from metallurgical plants, transport and local district heating are known to harm human health and the environment. Ostrava and its immediate vicinity regularly exceed air pollution limits due to its geomorphologic location and the presence of heavy industry. Maximum exceedances of air quality standards and especially $\mathrm{PM}_{10}$ 24-hour limit are still being frequently exceeded. In the year 2011 EU maximum air quality limits for $\mathrm{PM}_{10}\left(50 \mu \mathrm{g} \cdot \mathrm{m}^{-3}\right)$ were exceeded 126 times. It is important from a toxicological and health risk point of view both to identify sources of air pollution and also to find out maximum information about the nature of aerosols including; size distributions, chemical composition of individual size fractions, morphology of particulate matter. These should also be linked together with other parameters such as meteorological conditions and time of year. In this study some selected preliminary results from a larger project are presented focusing particularly on metal distributions in airborne dust.

The situation has in the Ostrava region certain specific features which exacerbate the accumulation of airborne pollution under certain weather conditions. For example, in the Ostrava-Radvanice suburb the maximum number of days that the $\mathrm{PM}_{10} 24$ hour average of $50 \mu \mathrm{g} / \mathrm{m}^{3}$ can be exceeded in one year (35) was already exceeded by the $18^{\text {th }}$ February 2013.

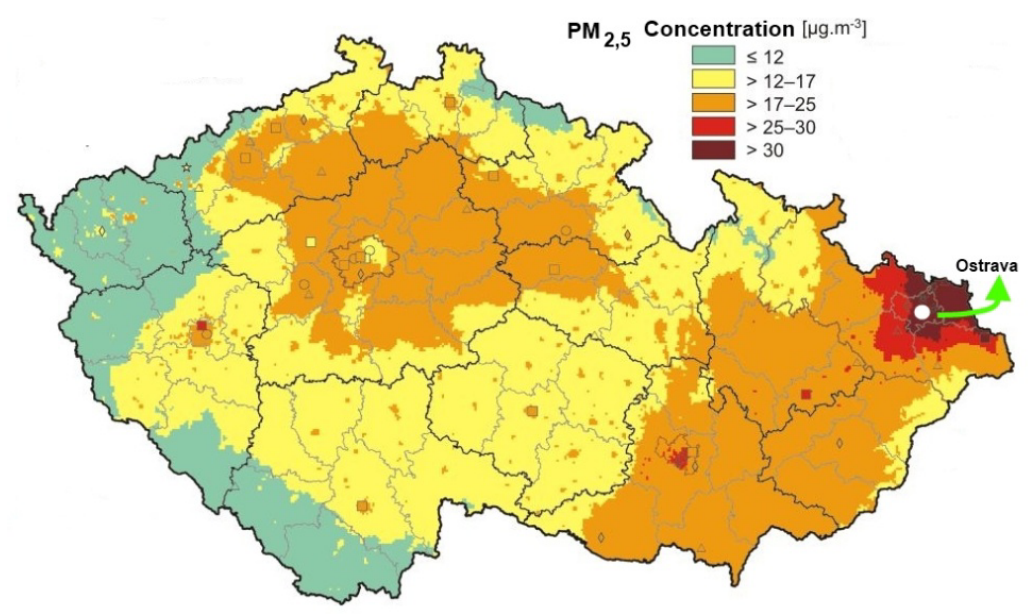

Figure 1: 2011 annual average concentration map of $\mathrm{PM}_{2.5}$. 
The annual average concentration of $\mathrm{PM}_{2.5}$ is clearly seen on Figure 1 [1]. This map represents also a typical view on Ostrava's industrial pollution during the winter inversion period. It is obvious that this area is by far the most polluted region in the Czech Republic.

Airborne particles or aerosols that are less than $100 \mu \mathrm{m}$ in size are collectively referred to as total suspended particulate matter (TSP). These particles constantly enter the atmosphere from many sources. Suspended particulate matter of anthropogenic origin has three main sources:

- Industry.

- Transport.

- Combustion products from space heating.

The location that is the subject of this study has a long industrial history that dates back to the 19th century. During this period, there were extensive metallurgical, chemical and coal mining industries. Nowadays two large metallurgical plants continue to work close to the town centre. A coking plant and a chemical plant are still operational in one location. In addition this region has from a geomorphologic point of view a disadvantageous location featuring a closed valley to the South and a wide open topography to the North. On the Polish side of the border, at distance of approximately $150 \mathrm{~km}$, there are many coal mines and metallurgical plants together with many local district heating units. These conditions often cause deterioration in air quality particularly during adverse winter weather conditions. This so called inversion may last up to two weeks or even longer. The local population is during this time exposed to conditions which have an extremely adverse effect on health.

Correlation between the occurrence of metals in ambient air and the incidence of cancer has been studied by many authors [2, 3]. Several heavy metals including arsenic, cadmium, chromium, nickel and zinc have been implicated in the increased risk of lung cancer. The heavy metals; cadmium, lead and mercury are common air pollutants, being emitted mainly as a result of various industrial activities. Heavy metals are persistent in the environment and accumulate in food-chains. Cadmium is considered to be a representative of highly toxic elements where the main anthropogenic sources include non-ferrous metal production, stationary fossil fuel combustion, waste incineration, iron and steel production and cement production. In addition to the total concentration of metals contained in atmospheric aerosol it is gaining increasing recognition that the size and mass distribution of inorganic and organic species and compounds is of significance. This is due to new knowledge which is becoming generally accepted that, as a rule, danger and toxicity increases with decreasing particle size. In this regard, many studies have been published demonstrating the toxicity of metals, such as manganese, zinc and copper (Samet et al. [4]). Results of some studies (Ghio [5]) indicate the catalytic effects of both the water-soluble and insoluble fractions of particulate atmospheric matter on oxidative stress. Adamson et al. [6] in their work showed that zinc salts alone induced an increase in inflammatory cells and protein in lung lavage fluid together with increased DNA synthesis in lung cells at this time, indicating a reparative response. 
There is currently a strong demand from state and local authorities to identify and recognize the main sources of airborne pollution. In ambient air of Ostrava not only particulate matter is present but also other gaseous and organic pollutants like benzo[a]pyrene.

This study is focused on occurrence of the size dependent distribution of selected metals in ambient air. The total concentration of selected toxic metals in the local air in $\mathrm{PM}_{10}$ fraction has been measured for many years. Until now, only limited information exists on nanoparticles emissions originating from various human activities and industry. Even more rare is information on size dependent distributions of metals in suspended particulate matter. This knowledge should help us to identify the main sources of persistent pollution and better understand and predict the potential risk to the population living in urban and industrial areas. There is also a lack of relevant information on which components of particulate matter have the greatest impact on public health by source, composition and size. Information is still unsatisfactory and inconclusive despite significant progress being made in the recent past and is compounded by the fact that particles can originate through natural (atmospheric formation), incidental (side product of anthropogenic activities) and engineered processes (deliberately produced with specific properties, having at least one dimension in the $1-100 \mathrm{~nm}$ range). It is generally found that the particles below $100 \mathrm{~nm}$ and below $300 \mathrm{~nm}$ contribute over $80 \%$ and $99 \%$ of total particle number concentration, respectively [7].

The main task of this study was to carry out at least three measuring campaigns during the year, targeting the times of an exceptional and/or unfavourable weather situation combined with increased $\mathrm{PM}_{10}$ concentrations. There are several stationary measuring systems monitoring not only the pollution by particulate matter but also other organic a gaseous pollutants in Ostrava and its suburbs. Some of those stations are operated by the Institute of Public Health in Ostrava and the results are continuously displayed on the Internet. Therefore deteriorating dispersion conditions may be predicted a few days in advance. However, this main condition was not always met due to technical and time constraints. Above all we were not able to measure and collect samples when the outdoor temperature dropped below $5^{\circ} \mathrm{C}$. Nevertheless some campaigns were completed and since the initial results are of significance the authors decided to publish them.

\section{Measurement and sampling}

The main objective of measurements was to determine what the size dependent distribution of toxic metals is in Ostrava's ambient air. It is intended to compare these results later with other data available from stationary monitoring $\mathrm{PM}_{10}$, $\mathrm{PM}_{2.5}, \mathrm{PM}_{1}, \mathrm{SO}_{2}, \mathrm{O}_{3}$ and data on meteorological conditions.

The measuring campaign started on $1^{\text {st }}$ February 2011, and was completed on $15^{\text {th }}$ March 2013. Four sampling cases occurred in 2011, two in 2012 and two in 2013. 


\subsection{Particle sample collection}

A wide-range aerosol sampling system Nano-ID Select was used for collecting samples over the entire size range for chemical analyses and for electron microscopy analysis. This size-selective sampling system allows the collection of samples separately on 12 stages (Gorbunov et al. [8]). The Nano-ID Select wide range aerosol sampler uses a combination of cascade impactors for micron size particles and diffusion screens for nanoparticles and has a sampling flow rate of $20 \mathrm{l} / \mathrm{min}$. Samples can be collected in the impaction stages directly onto scanning electron microscopy (SEM) grids. Using special holder for TEM grids into the diffusion cell was very troublesome and gave unsatisfactory results. A reliable method for sampling ultrafine aerosols of ambient air for SEM/TEM analyse is being still investigated.

\subsection{Analysis samples on SEM/EDS}

Scanning electron microscope ([SEM] QUANTA 450 FEG, FEI Company, WA) equipped with BSE, LFD and ETD detectors and integrated with EDAX energy dispersive spectroscopy (EDS) detector for microanalysis was used for observation of surface topography of particles and chemical composition of individual particles. In the case of electrically non-conductive particles low vacuum techniques and the presence of water vapour in the atmosphere of microscope chamber was primarily used for better resolution and contrast.

\subsection{Chemical analysis of collected particulate aerosol}

The samples collected by Nano-ID Select were analysed for metal content on ICP-MS, THERMO XSeries II. Prior to analysis samples were mineralized using the microwave system (Milestone MLS 1200 Mega, Milestone Inc., CT). Standard analytical procedures for samples of dust collected from the air on polymer or quartz filters and membranes were used. Digestion was carried out in closed vessels preventing loss of volatile elements like As or Sb. The glass slides from impactor stages and polymer membranes (nets) from the diffusion cell of the Nano-ID sampler were placed into the vessels of the microwave oven and $5 \mathrm{ml}$ of concentrated nitric acid $+1 \mathrm{ml}$ hydrogen peroxide added. The vessels placed into the microwave oven. The temperature of digestion is $180^{\circ} \mathrm{C}$ and is automatically controlled using a computer interface. The time of digestion at this temperature is 10 minutes. Once the digestion is complete, the samples are allowed to cool and then diluted with high-purity water to volume of $50 \mathrm{ml}$. Finally samples were analysed with ICP MS. Blank samples were digested and analysed in the same way as collected samples.

\subsection{Aerosol size distribution}

The particle number concentration was measured using a FMPS. This instrument covers a size distribution range from $5.6 \mathrm{~nm}$ to $30 \mu \mathrm{m}$ on 32 chancels (16 channels per decade) and has a fast response time of one second which is an 
essential requirement for acquiring size distributions of transient processes, resulting for example from a change of wind direction or the influence of transport such as passing vehicles close to the measuring post (Knutson and Whitby [9]). Functionality was always verified before starting the measurement by analyzing the incoming air with a prepended HEPA-filter.

\subsection{Sampling location}

There were chosen two places in Ostrava for sampling and measurement in this study as mentioned earlier. The first one (Ostrava - Marianske Hory) is situated in the centre of town in $500 \mathrm{~m}$ distance from a large steelworks (Evraz) adjacent to a kindergarten. The second one (Ostrava - Radvanice) is situated in a suburban area $1 \mathrm{~km}$ distance from a large metallurgical plant (ArcelorMittal). The Ostrava-Radvanice location is in a residential area with many district heating plants and it is often considered to be the most polluted area in this region. Olomouc town was chosen as a reference background level. It is situated in central Moravia, $100 \mathrm{~km}$ south of Ostrava, with no heavy industry in the vicinity.

\section{Results}

\subsection{Size-resolved chemical composition of aerosol}

Each stage from Nano-ID sampler was analyzed for more than 20 elements. For detailed evaluation only metals that are potentially toxic ( $\mathrm{Pb}, \mathrm{As}, \mathrm{Cd}, \mathrm{Ni}, \mathrm{Cr}, \mathrm{Mn}$ and $\mathrm{Zn}$ ) or are of interest for other reasons $(\mathrm{Fe}, \mathrm{Cu})$ were chosen.

Metals can be classified according to their mass-size distribution into three categories:

1. Distribution is very stable, single mode and does not depend on the location, season of the year or weather.

2. Distribution is highly variable for reasons which are not fully understood.

In this respect manganese exhibits a unique behavior - a very close agreement in distribution, independent of time and place of sampling. It is also remarkable that almost all of its mass is concentrated in the nano-range. To the other group of metals with variable distribution belongs e.g. nickel.

Taking into account the latest published works on the harmful effects of nanoparticles and oxides of manganese on human neural systems, Hobson et al [10], this could be a potentially serious finding. A typical distribution diagram of manganese is in Figure 2.

Chromium belongs also among metals exhibiting a relatively stable distribution with most of the mass concentrated in the nano-range with a significant peak at fraction from $23 \mathrm{~nm}$ to $100 \mathrm{~nm}$ (Figure 3). At first glance, there is an obvious similarity between these metals. 


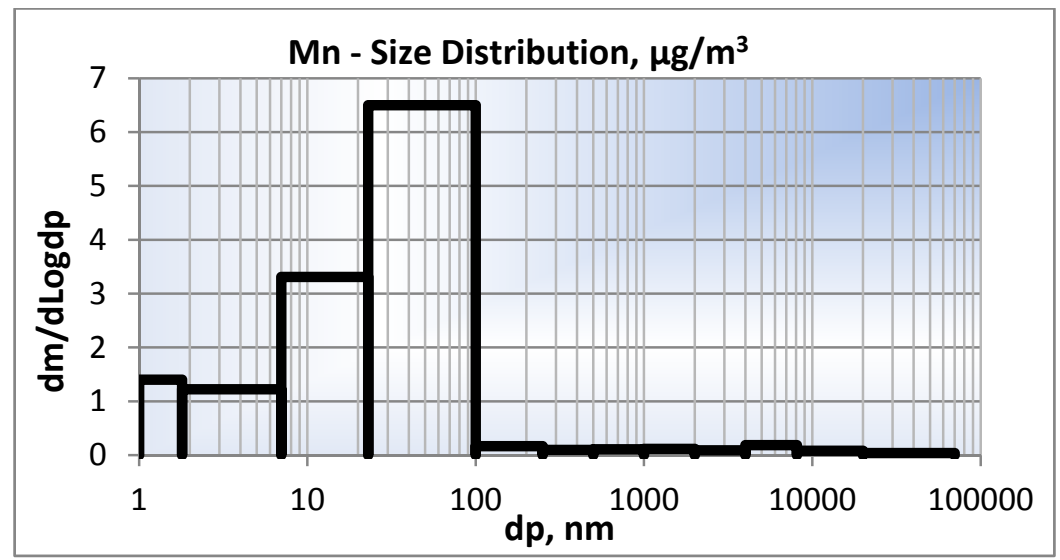

Figure 2: Mass aerosol size distribution for manganese in ambient air. Sampling performed 12th May 2011 in the Ostava-Radvanice location.

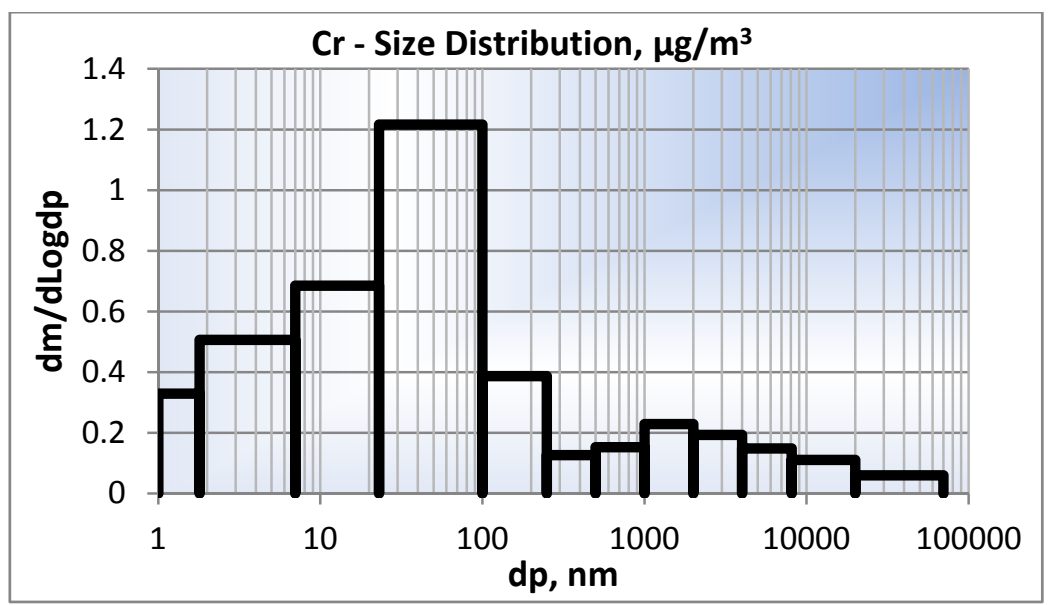

Figure 3: Example of mass aerosol size distribution for chromium in ambient air. Sampling performed 22nd October 2012 in the OstavaMarianske Hory location.

It has the same distribution also in Olomouc and the question is whether this is a general phenomenon. In the case of chromium, a probability of the presence of very toxic $\mathrm{Cr}(\mathrm{VI})$ is quite a high.

It may be that this phenomenon is typical for this region because we found the same distribution also in Olomouc town which was deemed a "clean" city. Natural sources may contribute significantly to this and local metallurgical plants 
only enrich their concentration level. The contribution of long-range transport must also be taken into account.

Other metals are found predominantly in fractions greater than $250 \mathrm{~nm}$. Lead and arsenic are typical representatives. These findings indicate that the main sources could be combustion products of black coal (Figure 4). The presence of larger agglomerates or heterogeneous particles with a high proportion of carbon black cannot be discounted.

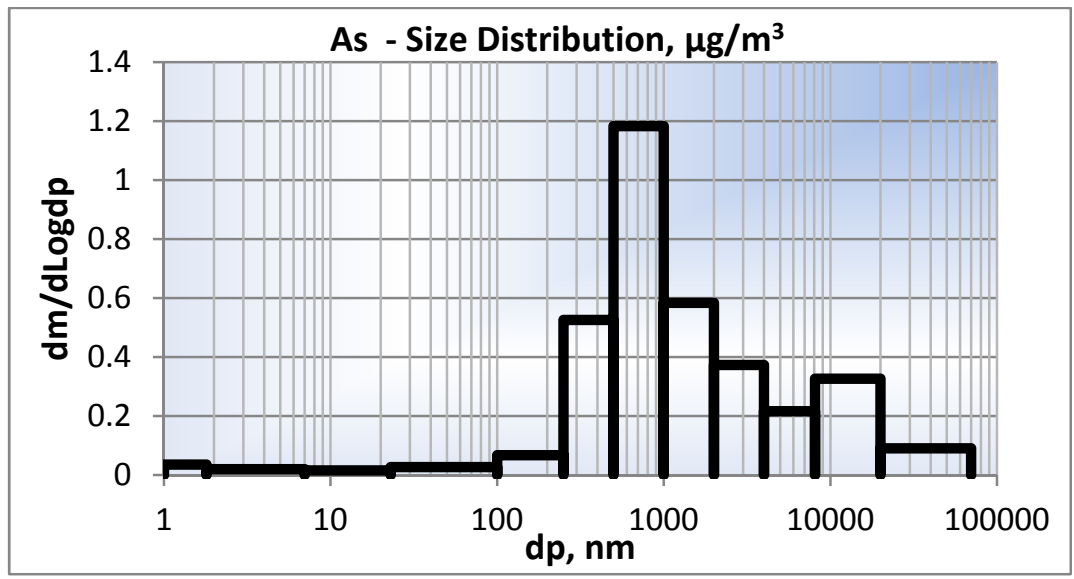

Figure 4: Example of mass aerosol size distribution for arsenic in ambient air. Sampling performed 7th September 2011 in the OstavaMarianske Hory location.

There are obvious differences in the total concentration of some metals caused probably by local sources. Amongst others, total concentration of zinc is higher in Ostrava-Marianske Hory with a typical size number concentration with a high maximum in the range from 100 to $250 \mathrm{~nm}$.

These are likely to be secondary particles as it is known from SEM observations, that in this size-region many agglomerates occur. Hence the source of this pollution is with high probability the nearby steelworks. Iron and steel production is accompanied by emission of considerable amounts of ultrafine aerosols containing a large proportion of metals, especially iron. Depending on their concentration, fine particles immediately form larger particles after entering into the atmosphere and this may be the case with zinc.

\subsection{Particle morphology}

A representative image from the SEM observations of aerosol taken up by Nano ID is presented in Figure 5.

The most interesting fractions come from range from $250 \mathrm{~nm}$ to $5 \mu \mathrm{m}$ and are predominantly represented by small spheres and crystals. Chemical composition analysis performed using EDS indicates major elements are iron and oxygen, implying inhomogeneous particles created by oxidation of molten iron droplets. 


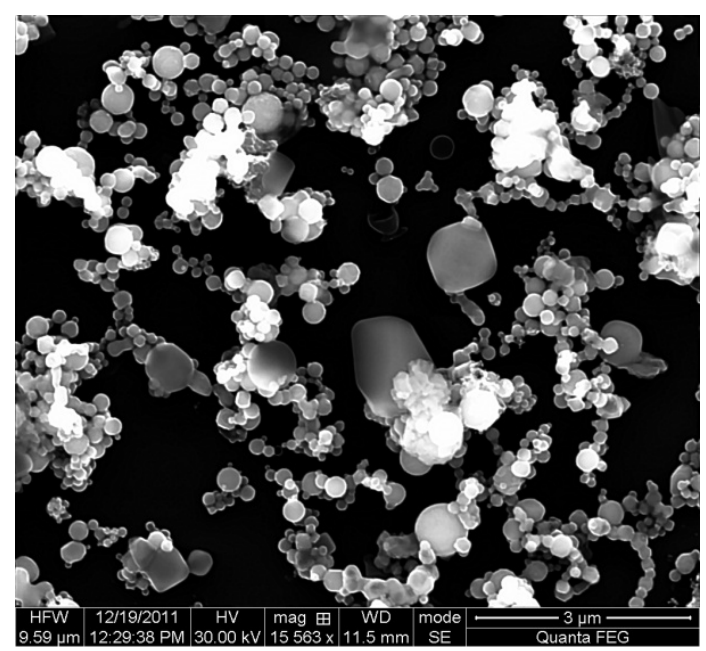

Figure 5: $\quad$ Image of fine aerosol; Nano ID stage $6(0.5$ to $1 \mu \mathrm{m})$, sampling 7 th November 2011, location: Ostrava-Radvanice

Crystals observed represent mainly two forms of iron oxide - magnetite (octahedron) and hematite (rhombohedra), under suitable meteorological conditions sodium chloride (cubic) and in one case crystals of ammonium sulphate were present in large numbers. However these salts are hygroscopic and temperature-sensitive. At the time of observation they were already almost wholly damaged and whilst focusing the electron beam they evaporated quickly, but EDS analysis confirmed higher sulphur and nitrogen content. In samples from the 7 th stage of the sampler $(0.25-0.5 \mu \mathrm{m}$ size $)$ small agglomerates in the form of chainlets (composed of more than fifty primary particles often smaller than $100 \mathrm{~nm}$ ) and clusters were observed. They were observed also clusters up to $1 \mu \mathrm{m}$ composed of smaller then $10 \mathrm{~nm}$ black carbon nanoparticles.

\subsection{Ultra-fine and fine aerosol particle size distribution}

Assessment of size distributions was done in the range of particle electrical mobility diameters from $5.6 \mathrm{~nm}$ to $560 \mathrm{~nm}$ during each measuring campaign by FMPS for approximately one hour period on each sampling site with $1 \mathrm{sec}$ response time. FMPS delivers valuable data on the evolution of particle size distributions and number concentrations. The FMPS provides a large amount of data requiring subsequent statistical evaluation taking into account meteorological conditions and seasonality. Simple visual analysis shows that in the majority of observed cases three mode distributions occur. The first one occurs with a maximum between $10 \mathrm{~nm}$ and $20 \mathrm{~nm}$; second one between $30 \mathrm{~nm}$ to $60 \mathrm{~nm}$ and the third between $150 \mathrm{~nm}$ to $200 \mathrm{~nm}$. 
a)

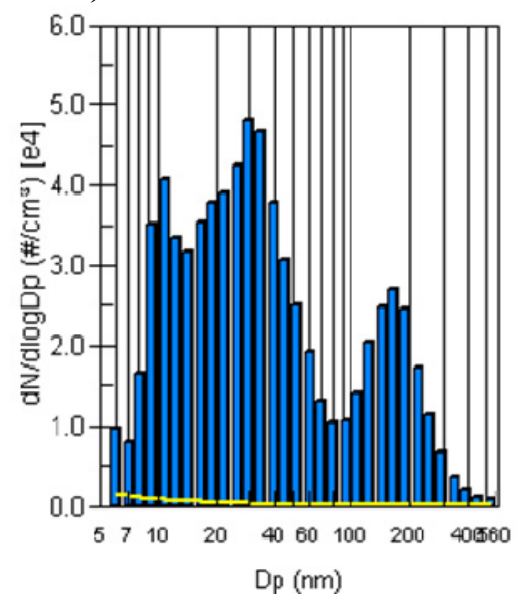

b)

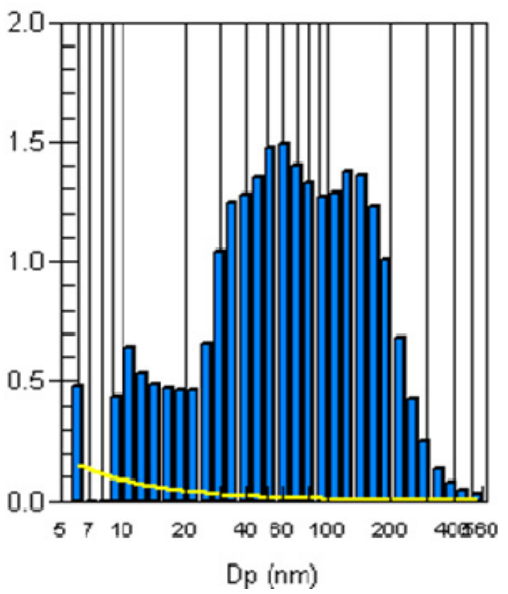

Figure 6: a) Diagrams of particle size distribution from FMPS, location Ostrava-Marianske Hory, measured on 1st February 2011 and b) 30th March 2011

Whereas the first two peaks are in range of nucleation mode and so called Aitken mode the last one mode represents agglomerates or aggregates. If one type of particles is present in high concentrations their mode can overlap the neighbouring one, resulting in one or two modal distributions. Figure 6 shows examples of size distributions.

\section{Conclusion}

Particle size dependant distributions of metals in samples of suspended particulate matter in Ostrava's ambient air were collected at two sites and analysed. Metals present in the samples can be divided into two main groups. The first group represents distributions which are very stable regardless of sample location, time and weather conditions and which are primarily composed of manganese and chromium. Both metals are concentrated in the nano-range. The second group which varies depending on location, time and weather conditions includes elements like nickel, iron and arsenic. From distribution patterns for arsenic and lead it can be concluded that these metal emissions originate from burning of fossil fuels. Morphology and chemical composition of sampled particles on SEM suggests the large share of iron and oxygen in particulate matter corresponds to the presence of magnetite and hematite. Three modal particle size distributions were documented in range $5.6 \mathrm{~nm}$ to $560 \mathrm{~nm}$ with peaks in range $10 \mathrm{~nm}$ to $20 \mathrm{~nm}$, between $30 \mathrm{~nm}$ to $60 \mathrm{~nm}$ and between $150 \mathrm{~nm}$ to $200 \mathrm{~nm}$. 


\section{References}

[1] Portal of Czech Hydrometeoroligical Institute, http://portal.chmi.cz $/$ portal $/ \mathrm{dt}$

[2] Coyle, Y.M., Minahjuddin, A.T., Hynan, L.S. \& Minna, J.D., An ecological study of the association of metal air pollutants with lung cancer incidence in Texas. J Thorac Oncol. 1(7), pp. 654-61, 2006.

[3] Luo, J., Hendryx, M. \& Ducatman A., Association between six environmental chemicals and lung cancer incidence in the United States. J Environ Public Health. 2011, 2011 Online. http://www.hindawi.com /journals/jeph/2011/463701

[4] Samet, J.M., Avila-Tang E., Boffetta, P., Hannan, L.M., Olivo-Marston, S., Thun, M.J. \& Rudin, C.M., Lung cancer in never smokers: clinical epidemiology and environmental risk factors, Clinical Cancer Research, 15(18), pp. 5626-5645, 2009.

[5] Ghio, A.J., Metals associated with both the water-soluble and insoluble fractions of an ambient air pollution particle catalyze an oxidative stress, Inhalation Toxicology. 11(1), pp. 37-49, 1999.

[6] Adamson, I.Y.R., Prieditis, H., Hedgecock, C. \& R. Vincent, Zinc is the toxic factor in the lung response to an atmospheric particulate sample. Toxicology and Applied Pharmacology. 166(2), pp. 111-119, 2000.

[7] Heal, M.R., Kumar, P. \& Harrison, R.M., Particles, air quality, policy and health. Chemical Society Reviews 41, pp. 6606-6630, 2012.

[8] Gorbunov, B., Priest, N.D., Muir, R.B., Jackson P.R. \& Gnewuch, H., A Novel Size-Selective Airborne Particle Size Fractionating Instrument for Health Risk Evaluation, Ann. Occup. Hyg. 53(3), pp. 225-237, 2009.

[9] Knutson, E.O. \& Whitby, K.T., Aerosol Classification by Electric Mobility: Apparatus Theory and Applications. Journal of Aerosol Science. 6(6), pp. 443-451, 1975.

[10] Hobson, A., Seixas, N., Sterling, D. \& Racette, B.A., Estimation of particulate mass and manganese exposure levels among welders. Ann. Occup. Hyg. 55(1), pp. 113-125, 2010. 